\title{
ESTIMATING THE SHELF LIFE OF FLAVOURING OIL GRAVY CONSISTING OF RED PALM OIL
}

\section{GUANGYI GONG ${ }^{1}$; XIAOJING WU1; SHIMIN WU ${ }^{1,2 *}$; JUNHAO YOONG ${ }^{3}$, MIN JI $^{3}$ and MINGMING HU}

\begin{abstract}
The nutritional quality and sensory properties of flavouring oil gravy enclosed in instant noodle products have aroused great attention. In this study, we investigated the effects of the replacement of tallow with red palm oil (RPO) on the shelf life of flavouring oil gravy between one commercial sample and two pilot samples with different ingredients. The quality of the three gravy samples during the accelerated shelf-life test was evaluated by sensory properties using a spectrophotometer for colour measurement and sensory evaluation. In addition, the acid value $(A V)$ and peroxide value (POV) dynamic equations of flavouring oil gravy were monitored. The shelflife of the two pilot samples was predicted using Arrhenius models. The results indicated that compared with the flavouring oil gravy of commercial stewed beef (CSB), only one-third to one- half of the colour differences were observed in the other two pilot gravies. The predicted shelf lives of experimental stewed beef and experimental sour soup were $33.33 \%$ and $33.33 \%$ longer, respectively, than CSB at a storage temperature of $20^{\circ} \mathrm{C}$. These results may help predict the shelf life of flavouring oil gravies and innovate the diversity of RPO in the food industry.
\end{abstract}

Keywords: accelerated shelf-life testing, Arrhenius model, instant noodle.

Received: 21 July 2021; Accepted: 27 December 2021; Published online: 15 February 2022.

\section{INTRODUCTION}

Instant noodles are an important constitution of diet worldwide, especially in East and Southeast Asian countries (Gulia et al., 2014). This popularity is attributed to their desirable flavour, affordable price and rapid preparation. However, great concerns also emerge with the overconsumption

Department of Food Science and Technology,

School of Agriculture and Biology,

Shanghai Jiao Tong University,

800 Dongchuan Road,

Shanghai 200240, China.

2 Key Laboratory of Urban Agriculture (South), Ministry of Agriculture,

800 Dongchuan Road,

Shanghai 200240, China.

3 Palm Oil Research and Technical Service Institute of Malaysian Palm Oil Board (PORTSIM), Shanghai 201108, China.

* Corresponding author e-mail: wushimin@sjtu.edu.cn of instant noodles (Huh et al., 2017). With the aim of meeting the health demands and reassuring the increasing health concerns of consumers, it is necessary to develop new products with novel ingredients and, more importantly, with higher quality.

Flavouring oil gravy, which accounts for $10 \%-20 \%$ of the total weight of the instant noodle product, has a significant impact on its sensory quality. These gravies not only provide consumers with pleasant aroma and taste but also contribute to the energy and nutritional value to a great extent. Furthermore, the oil content in flavouring oil gravy makes up to nearly $50 \%$ of the weight. Therefore, the oil used in flavouring oil gravy plays a critical role in the overall quality of instant noodles. Traditionally, animal fats rich in saturated fat are widely used in commercial flavouring oil gravy. However, with an increasing number of ethnic consumers preferring food products without animal fat, it is an emerging trend to develop an 
alternative way to replace animal fat. In addition, a high intake of saturated fat is generally recognised as the main cause of cardiovascular diseases (Wang and $\mathrm{Hu}, 2017)$. Therefore, it is essential to find a sophisticated way to reduce the potential health risk of flavouring oil gravy and simultaneously maintain flavour and colour.

Palm oil with high thermal stability is considered an ideal alternative for the instant noodle frying industry. A high content of n-6 unsaturated fatty acids in palm oil also reduces the risk of cardiovascular diseases (Wang and $\mathrm{Hu}, 2017)$. In addition to the benefits of palm oil, red palm oil (RPO) has the further advantage of possessing more abundant natural antioxidants, including over 20 types of different carotenes. Carotenes with high content and diversity present in RPO give this refined oil a typical orange-red colour (Oguntibeju et al., 2009), which is close to those of gravies made of animal fats. Due to the abundant content of various kinds of carotenoids, RPO has been used to prevent children and women from potential vitamin A deficiency. In addition, it also helps patients with liver cirrhosis regulate their oxidative stress. Moreover, people who suffer from cystic fibrosis may also benefit from the intake of RPO since it can increase the concentrations of $\beta$-carotene and retinol (Burri, 2012; Catanzaro et al., 2016). In addition to carotene, palm oil is abundant in various kinds of vitamin E, including $\alpha$-tocopherol, $\quad \alpha$-tocotrienol, $\quad \gamma$-tocopherol, $\gamma$-tocotrienol, $\delta$-tocopherol and $\delta$-tocotrienol (David et al., 2000; Ng et al., 2004). A previous study indicated that the total concentration of $\alpha$-tocopherol, as well as $\alpha-, \gamma-$, and $\delta$-tocotrienol, in RPO reached $955 \mathrm{mg} / \mathrm{kg}$ (Yi et al., 2011). Using rat model experiments, researchers observed the attenuation of cytotoxic effects as well as the increasing threshold for ventricular fibrillation with the intake of RPO (Katengua-Thamahane et al., 2014; Wergeland et al., 2011). In our previous study (Wu et al., 2018), RPO enhanced the carotenoid content of flavouring oil gravy, and delightfully, it had a negligible adverse impact on the sensory qualities. Therefore, without the loss of the original flavour, the nutritional quality and oxidation resistance of the gravy were enhanced with the replacement of RPO. However, the effects of RPO on the shelf life of flavouring oil gravies were not investigated in that study.

Shelf life has been generally recognised as an important factor of food for a long time. It can be defined as the length of time during which food products can be stored without their quality becoming unacceptable to consumers (Calligaris et al., 2016). Generally, the determination of the shelf life of food is considered time-consuming. However, with the introduction of accelerated shelf life testing (ASLT), the determination time can be largely reduced (Mizrahi, 2000). Usually, there are three fundamental steps that constitute typical ASLT. First, a group of indicators need to be selected, which can be used to reflect product quality. Second, changes in indicators that are selected in the first step need to be observed. Third, an appropriate kinetics model needs to be set after the collection of data from step 2. Subsequently, an equation also needs to be established to predict the shelf life (Manzini et al., 2017).

In the present study, we evaluated changes in the sensory properties of flavouring oil gravy by colour differences and sensory evaluation. In addition, the acid value (AV) and peroxide value (POV) dynamic equations of flavouring oil gravy were monitored by the Arrhenius model during ASLT. We also compared the predicted shelf life with those of actual flavouring oil gravies stored at room temperature for eight consecutive months.

\section{MATERIALS AND METHODS}

\section{Materials}

The RPO used in this study was specially refined and supplied by Carotino Sdn. Bhd. (Johor, Malaysia). The two other commonly used palm oils $\left(5^{\circ} \mathrm{C}\right.$ and $\left.8^{\circ} \mathrm{C}\right)$ were supplied by Tianjin Longwei Co., Ltd. (Tianjin, China). The slip melting point of $\mathrm{RPO}$ was $5^{\circ} \mathrm{C}$, while the melting points of the two other palm oils were $5^{\circ} \mathrm{C}$ and $8^{\circ} \mathrm{C}$.

Based on the survey we established previously on market data and consumer preferences, commercial stewed beef (CSB) flavouring oil gravy was chosen for experiments and bought from the market. The ingredients of CSB are tallow (60\%), beef paste $(15 \%)$, thick broad-bean sauce $(15 \%)$, chive oil $(5 \%)$, five spice powder $(1 \%)$, beef extract paste $(1 \%)$, soybean sauce $(1 \%)$, cooking wine $(1 \%)$ and salt $(1 \%)$. The shelf life of CSB is 180 days, as shown by the food label. For comparison, two other flavouring oil gravies, including experimental stewed beef (ESB) and experimental sour soup (ESS), were used in this experiment. The ingredients in ESB include palm oil $(60 \%)$, beef paste $(15 \%)$, thick broad-bean sauce $(15 \%)$, chive oil $(5 \%)$, five spice powder $(1 \%)$, beef extract paste $(1 \%)$, soybean sauce $(1 \%)$, cooking wine $(1 \%)$ and salt $(1 \%)$. The ingredients in ESS include palm oil $(60 \%)$, beef paste $(20 \%)$, thick broad-bean sauce $(10 \%)$, diced needle mushroom $(5 \%)$, five spice powder $(1 \%)$, beef extract paste $(1 \%)$, vinegar $(1 \%)$, soybean sauce $(1 \%)$, and salt $(1 \%)$. Palm oil was first heated to $160^{\circ} \mathrm{C}$ and mixed with pastes and seasonings. Then, the mixture was pan-fried for 
$3 \mathrm{~min}$ and cooled to $40^{\circ} \mathrm{C}$. Finally, the products were packed in polyethylene terephthalate bags.

\section{Experimental Design for the Prediction of Shelf Life}

Each type of flavouring oil gravy was prepared and packed in polypropylene bags. In total, 300 bags (100 bags of each type of gravy) of the flavouring oil gravies were stored at four temperatures: $4^{\circ} \mathrm{C}$, $25^{\circ} \mathrm{C}, 37^{\circ} \mathrm{C}$ and $45^{\circ} \mathrm{C}$ ( 25 bags from each type of gravy stored at a specific temperature). In this study, the gravies were consecutively stored for 63 days. The quality and safety indices of the samples were monitored at $0,7,14,21,28,35,49$ and 63 days.

The reaction constant, $k_{n^{\prime}}$ was calculated based on oxidation indices, i.e., the $\mathrm{AV}$ and $\mathrm{POV}$, using the Equation (1):

$$
\ln N=\ln N_{0}+k_{n} \cdot t
$$

where $N_{0}$ is the initial value of the oxidation index at different storage temperatures, $N$ is the oxidation index value at different storage temperatures after storage, and $t$ is the storage time.

The temperature dependence of the deterioration rate, $k_{n^{\prime}}$ is then modelled by the Arrhenius Equation (2):

$$
\ln k_{n}=\ln k_{0}-\frac{E}{R T}
$$

where $k_{0}$ is the change in the rate of the respective quality index at a reference temperature, $T$ is the storage temperature $(\mathrm{K}), \mathrm{E}$ is the activation energy of the studied action $(\mathrm{J} / \mathrm{mol})$, and $\mathrm{R}$ is the universal gas constant of $8.314 \mathrm{~J} /(\mathrm{mol} \cdot \mathrm{K})$.

\section{Extraction of Oils from Commercial and Pilot Flavouring Oil Gravies}

The extraction process of oils was reported in our previous study (Wu et al., 2018). Briefly, $10 \mathrm{~g}$ of each sample was put in a glass flask before being dissolved in $100 \mathrm{~mL}$ of $\mathrm{n}$-hexane. The mixture was sonicated for $1 \mathrm{hr}$, and then the supernatant was transferred from the flask into a Soxhlet extractor. The ultrasound extraction process was repeated three times. Subsequently, excess solvent stored in the Soxhlet extractor was removed under vacuum conditions at $45^{\circ} \mathrm{C}$ with the assistance of a rotary evaporator (Yuanhuai Chemical Technology Co., Ltd, Shanghai, China). Residual oil in the extractor was absorbed by a dropper and then transferred into a $15 \mathrm{~mL}$ plastic centrifuge tube. Samples were kept in the dark at $-20^{\circ} \mathrm{C}$ prior to analysis.

\section{Analysis of $\mathrm{AV}$ and POV}

The AV and POV of oils were determined using a titrimetric method according to corresponding Chinese national standards (GB 5009.227; GB 5009.229) Chinese Standard (2016a); Chinese Standard (2016b). For AV, a $2.5 \mathrm{~g}$ extracted oil sample was dissolved in $50 \mathrm{~mL}$ of ether/isopropanol $(1: 1, v: v)$. The mixture was neutralised using $\mathrm{KOH}$ at a concentration of $0.1 \mathrm{~mol} / \mathrm{L}$. The result was represented in units of $\mathrm{mg} / \mathrm{g}$. For POV, a $2.5 \mathrm{~g}$ extracted oil sample was dissolved in $30 \mathrm{~mL}$ of chloroform/acetic acid $(2: 3, v: v)$. Then, $1 \mathrm{~mL}$ of saturated potassium iodide (KI) solution was added to the solution and stored in the dark for $3 \mathrm{~min}$. Finally, $100 \mathrm{~mL}$ of water was added to the solution, and then, it was titrated using a $\mathrm{Na}_{2} \mathrm{~S}_{2} \mathrm{O}_{3}$ solution at a concentration of $0.002 \mathrm{~mol} / \mathrm{L}$. The result was represented in units of $\mathrm{g} / 100 \mathrm{~g}$.

\section{Determination of Colour}

To clearly describe the colour changes during storage, colour measurements were performed using a PilotScan spectrophotometer (Hunterpilot, Reston, VA, USA). $\mathrm{L}^{*}, \mathrm{a}^{*}$ and $\mathrm{b}^{*}$ values were used to express the result (Antonis, 2019). Measurements were repeated three times, and the mean value was calculated. Additionally, the brightness or vividness of colour was also determined, and the results were expressed using chroma $\left(C^{*}\right)$. The $C^{*}$ value can describe the colour saturation of the samples, in which the initial value is 0 , and was calculated using the formula $C^{*}=\left(a^{* 2}+b^{* 2}\right)^{1 / 2}$. In contrast, $\Delta \mathrm{E}$ was used to describe colour differences and was calculated using the Equation (3):

$$
\Delta E=\left[\left(L^{*}-L_{r e f}^{*}\right)^{2}+\left(a^{*}-a_{r e f}^{*}\right)^{2}+\left(b^{*}-b_{r e f}^{*}\right)^{2}\right]^{1 / 2}
$$

\section{Sensory Panel Evaluation}

The sensory evaluation of the samples in this study was carried out according to our previous method (Wu et al., 2018). A panel of 12 judges was composed of six semi-trained students and six trained employees (seven males and five females between the ages of 20 and 50 years old). Instruction was provided at the beginning of the first evaluation session, which lasted approximately $30 \mathrm{~min}$ (Kwak et al., 2015).

Each flavouring oil gravy sample was stored in the dark at room temperature and opened immediately before sensory analysis. Disposable coded paper cups were offered to each panellist, along with a scorecard. Five grams of each sample was placed on a transparent vessel for evaluation of appearance (presence of impurities and appearance of organisation). Additionally, $5 \mathrm{~g}$ samples were dissolved in $1 \mathrm{~L}$ of boiling water for the evaluation 
of colour, and $5 \mathrm{~g}$ samples were added to $500 \mathrm{~mL}$ of boiling water for the evaluation of odour and taste. For each product, the panellists scored five perceived attributes from weak (1) to strong (10), which included colour, texture, odour, flavour and durance of fragrance.

Evaluations were performed at room temperature $\left(18^{\circ} \mathrm{C}-20^{\circ} \mathrm{C}\right)$ under natural light. To minimise fatigue and standardise the assessment process, a rigorous tasting and rinsing procedure was established. Panellists were asked to smell and taste the flavouring oil gravy sample in the mouth for 4-5 s, spit, and then fill out the scorecard. Panellists were then asked to rinse their mouth with water, eat a piece of bread or Melba toast, rinse again with water, and wait $1 \mathrm{~min}$ before proceeding to the next sample.

\section{Validation of the Predicted Shelf Life}

To verify the predicted shelf life calculated using the Arrhenius equation, 50 bags each of ESS and ESB were prepared. The bags containing flavouring oil gravies were stored outside and protected from sunlight exposure to imitate the actual storage environment. It is worth mentioning that the 'room temperature' in this experiment refers to a changing external environment temperature rather than a constant temperature of $25^{\circ} \mathrm{C}$. The gravies were consecutively stored for eight months. The average temperatures in Shanghai from March to December 2017 were $11^{\circ} \mathrm{C}, 18^{\circ} \mathrm{C}, 23^{\circ} \mathrm{C}, 25^{\circ} \mathrm{C}, 32^{\circ} \mathrm{C}$, $31^{\circ} \mathrm{C}, 26^{\circ} \mathrm{C}, 22^{\circ} \mathrm{C}, 14^{\circ} \mathrm{C}$ and $8^{\circ} \mathrm{C}$. The quality and safety indices of the samples were monitored every month.

\section{RESULTS AND DISCUSSION}

\section{Colour Difference between Flavouring Gravies during Storage}

The colour of edible oil is one of the most critical indicators that can be used to monitor oil quality both visually and physically (Kim et al., 2015). As shown in Table 1, colour differences were presented using $\mathrm{C}^{*}$ and $\Delta \mathrm{E}$, which represented brightness of colour and colour differences, respectively. The results indicated that the brightest colour in flavouring oil gravy was exhibited by ESS, while the darkest was exhibited by ESB. This result was consistent with our previous research, which might result from the thick broad-bean sauce added in the formulation of ESB ( $\mathrm{Wu}$ et al., 2018). It is worth mentioning that the brightness in ESB and ESS gradually decreased with increasing storage temperature. The reduction in brightness may be attributed to the degradation of pigments (Alvarruiz et al., 2020). In contrast, a significant decrease was witnessed between the brightness in CSB at storage temperatures of $4{ }^{\circ} \mathrm{C}$ and $25^{\circ} \mathrm{C}$, while no obvious change was seen between those at $25^{\circ} \mathrm{C}, 37^{\circ} \mathrm{C}$ and $45^{\circ} \mathrm{C}$. The results indicated that oil gravies need to be kept in cold storage. Moreover, abundant carotenoids in ESB and ESS may prevent the degradation of other pigments, which leads to milder changes in brightness.

These results indicated that solid substances might disperse in the flavouring oil gravies, which resulted in a decrease in brightness. Increasing the storage temperature could also accelerate the process. However, no significant difference was found in the $\Delta \mathrm{E}$ for all three samples.

\section{Changes in Oxidation Indices in Flavouring Oil Gravies during Storage}

The oxidation of edible oils is one of the most important quality criteria in the food industry since hydroperoxides will be formed during both processing and storage and further decrease the nutritional quality of edible oils (Huyan et al., 2019). Changes in AV and POV in flavouring oil gravies during consecutive 63-day storage are shown in Table 2. It is predictable that both AV and POV increased with storage time and storage temperature. At the end of storage, the AVs and POV in all gravy samples were below the Chinese regulatory limit of edible oils.

For $\mathrm{AV}$, the initial values were $1.25 \mathrm{mg} / \mathrm{g}$ for ESB, $1.53 \mathrm{mg} / \mathrm{g}$ for ESS and $1.20 \mathrm{mg} / \mathrm{g}$ for CSB. The AVs for ESS were higher than those of the other two gravies during the whole storage period, which might result from the vinegar added in the ingredient panel of ESS. The other two gravies, ESB and CSB, witnessed a similar increasing trend during storage. The growth rates of ESB and ESS were $17.00 \%$ and $19.00 \%$ at $4{ }^{\circ} \mathrm{C}$ and $166.7 \%$ and $152.9 \%$ at $45^{\circ} \mathrm{C}$, respectively. In comparison, the growth rate of CSB was slightly higher, i.e., $20 \%$ at $4{ }^{\circ} \mathrm{C}$ and $170.8 \%$ at $45^{\circ} \mathrm{C}$. Vegetable oils rich in unsaturated fatty acids are generally regarded as more vulnerable to oil oxidation than animal oils with abundant saturated fatty acids. Our study indicates that the high content of carotenoids in palm oil not only gives a red colour similar to animal oil but also compensates for shortcomings of the tendency to oxidise.

In addition to the gravy type, the storage temperature also had a great impact on $\mathrm{AVs}$ and POVs during storage. Taking AV as an example, it took 63 days for the $\mathrm{AV}$ in the three gravy samples to reach an $\mathrm{AV}$ value of $1.42-1.72 \mathrm{mg} / \mathrm{g}$ at a storage temperature of $4^{\circ} \mathrm{C}$. In comparison, it took 28 days to reach a value of $1.42-1.78 \mathrm{mg} / \mathrm{g}$ at $25^{\circ} \mathrm{C}, 14$ days to reach $1.48-1.64 \mathrm{mg} / \mathrm{g}$ at $37^{\circ} \mathrm{C}$, and only seven days to reach $1.48-1.65 \mathrm{mg} / \mathrm{g}$ at $45^{\circ} \mathrm{C}$. It is widely reported that temperature storage has a great 


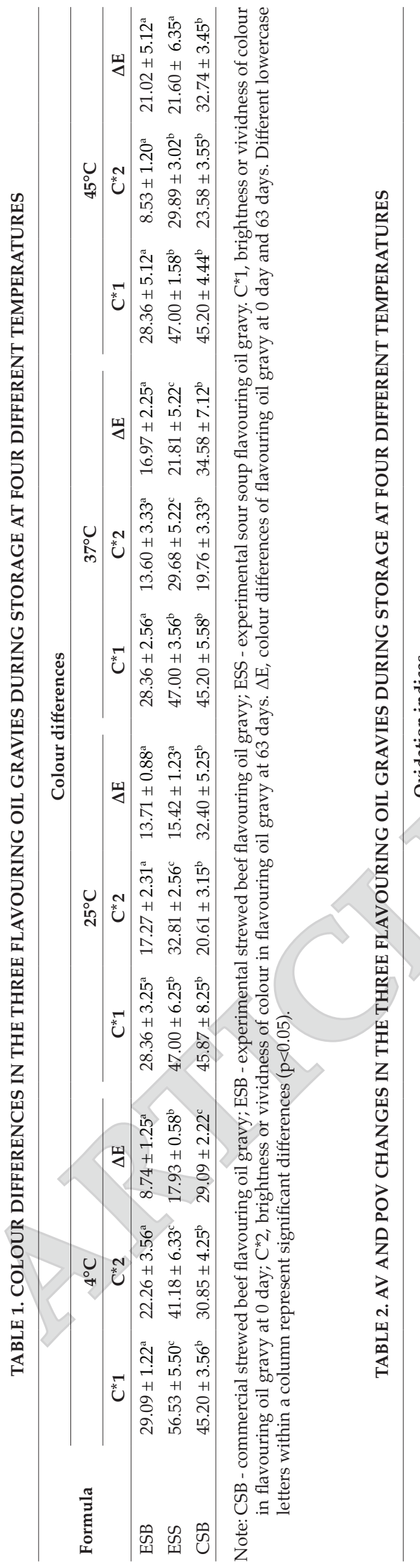

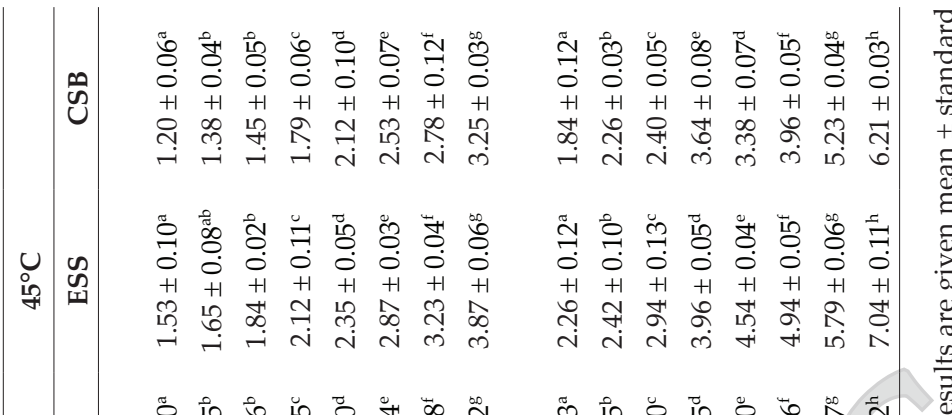

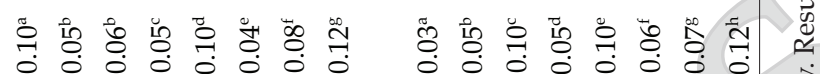

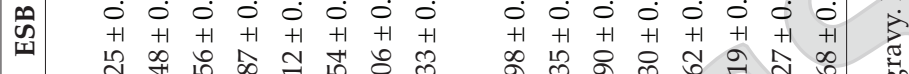

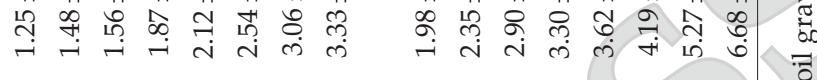

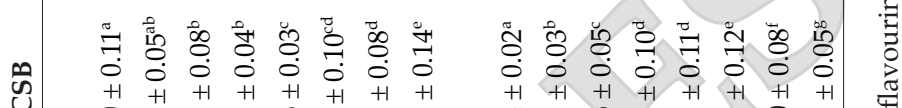

究

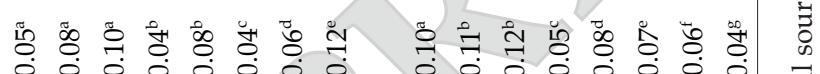

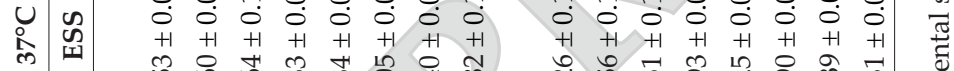

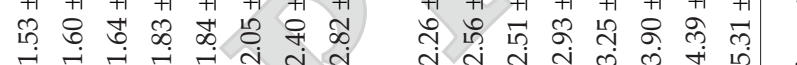

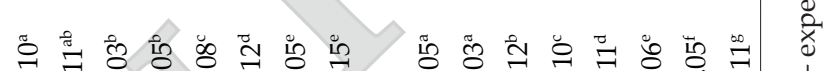

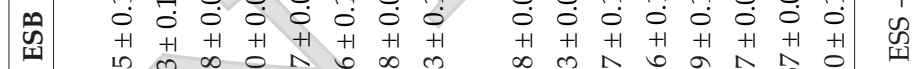

岱

窵

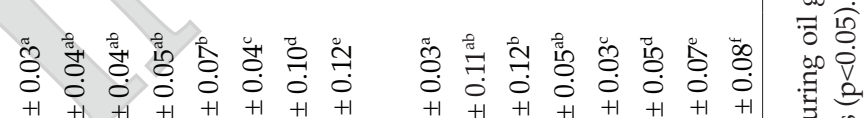

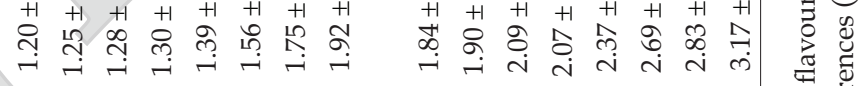

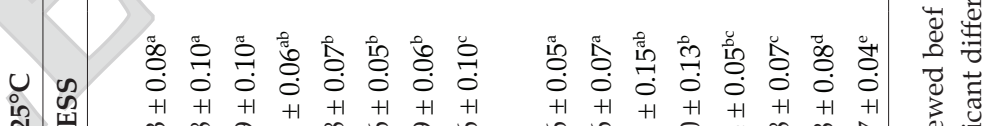

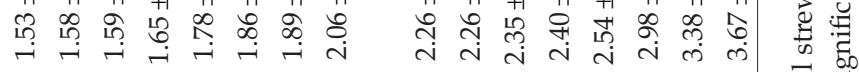

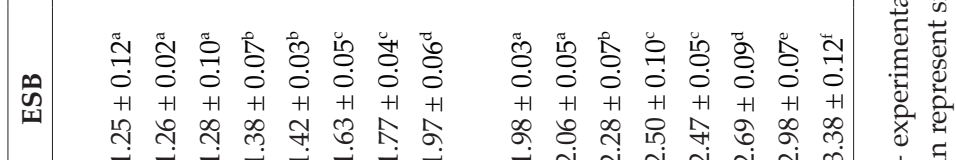

焉

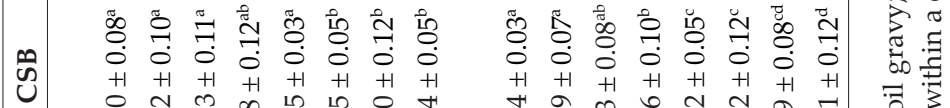

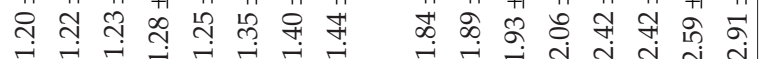

$\stackrel{\infty}{\infty}$

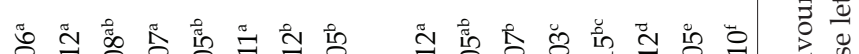

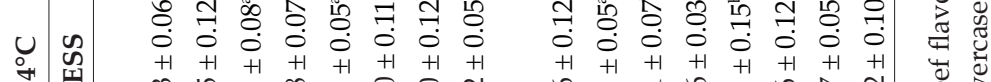

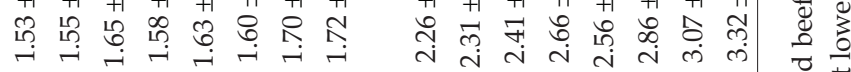

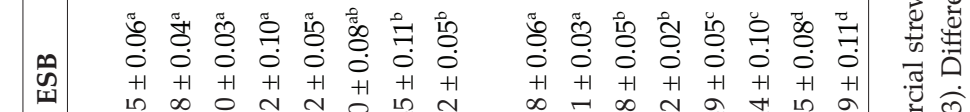

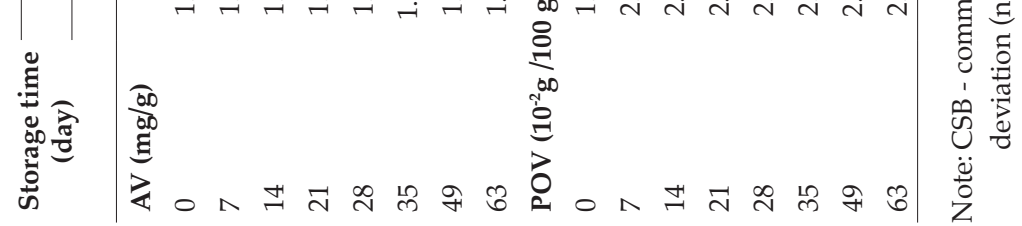


impact on the quality of edible oil, and high storage temperatures promote the rancidity of edible oil (Guiotto et al., 2014; Zhao et al., 2021). Similar effects were observed in the POV. These results remind us to prevent gravies from high-temperature storage, especially in summer.

\section{Calculation of the Kinetic Model and Prediction of Shelf Life}

$\mathrm{AV}$ and POV values are commonly used as indicators of oil quality. As discussed above, AV and POV changed significantly during consecutive storage. Therefore, to investigate the dynamic change of flavouring oil, we chose AV and POV to fit with the first-order kinetic equation. The results showed that all fitting coefficients were higher than 0.98, which indicated that the fitting model was reasonable and precise (Table 3).

The reaction constant $k_{n}$ increased with storage temperature. The effects were more obvious at storage temperatures higher than $25^{\circ} \mathrm{C}$. The reaction constant calculated using $\mathrm{AV}$ at $25^{\circ} \mathrm{C}$ was close to that at $4^{\circ} \mathrm{C}$. In comparison, $k_{n}$ doubled with an increasing storage temperature of $12^{\circ} \mathrm{C}\left(37^{\circ} \mathrm{C}\right)$ and increased by three times at $45^{\circ} \mathrm{C}$. A similar phenomenon was observed when we used the POV fitting model. Although room temperature of $25^{\circ} \mathrm{C}$ is commonly considered a storage temperature in daily life, the storage temperature may reach $40^{\circ} \mathrm{C}$ in practical use. The results of this study indicated that storage temperatures under $25^{\circ} \mathrm{C}$ could prevent oil-rich foods from rancidity to a great extent, while these foods need to be cooled in summer. Moreover, the variation in $k_{n}$ of the CSB samples was slightly higher than that of the other two gravy samples, which was consistent with the AV and POV results.

The Arrhenius formula indicates that there is a linear relation between lnk and 1 / T. Therefore, the equation of lnk and $1 / \mathrm{T}$ can be calculated according to the first-order reaction rates of four storage temperatures. The shelf life of these flavouring oil gravies at three different temperatures was further calculated. The first-order reaction rate constant at $25^{\circ} \mathrm{C}$ can be calculated with the substitution of $\mathrm{T}=$ $298.15 \mathrm{~K}$. Table 4 shows the parameters of the firstorder reaction kinetics equation and the predicted shelf life for each sample at three commonly used storage temperatures: $20^{\circ} \mathrm{C}, 25^{\circ} \mathrm{C}$ and $30^{\circ} \mathrm{C}$. The predicted shelf life lasted for six to eight months, and the results were consistent with the oxidation indices. In comparison, the labelled shelf life of CSB was 180 days, which is close to our estimation. The shelf life of ESS was slightly shorter than that of the other two gravies. In addition, the shelf life is shortened by 30 days for every $5^{\circ} \mathrm{C}$ rise in temperature.

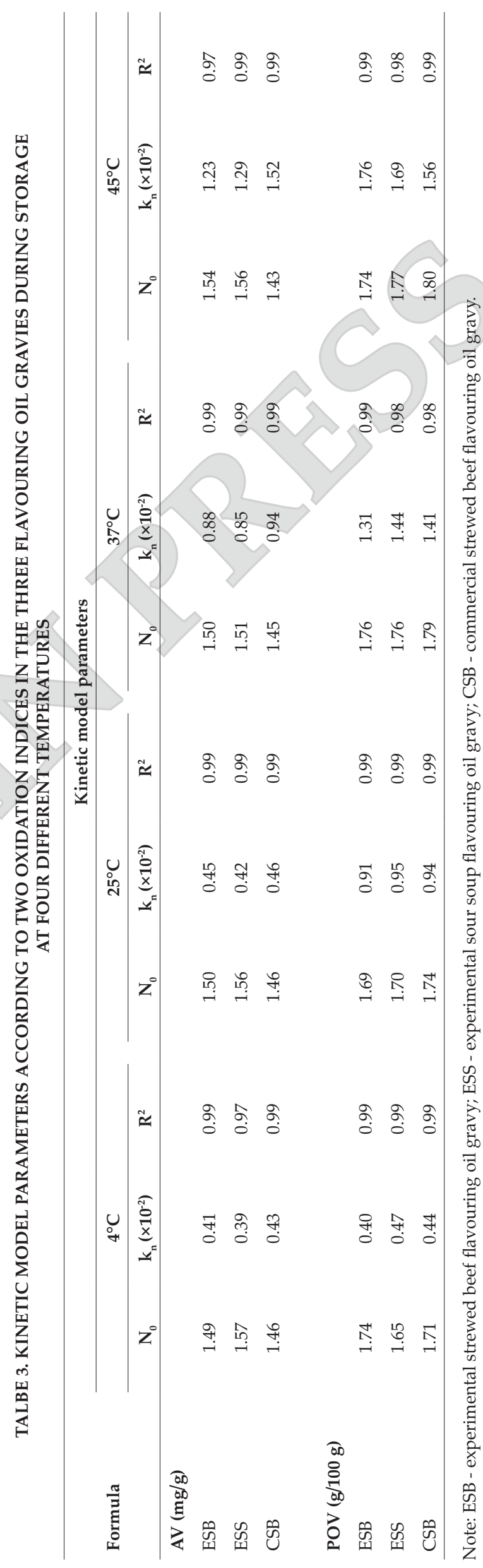


TABLE 4. THE SHELF LIFE OF THE THREE GRAVIES ACCORDING TO POV AT THREE TEMPERATURES

\begin{tabular}{|c|c|c|c|c|c|c|c|}
\hline \multirow{2}{*}{ Formula } & \multicolumn{7}{|c|}{ Kinetic model parameters } \\
\hline & $\mathrm{E}(\mathbf{k J})$ & $\mathbf{k}_{0}$ & $\mathbf{N}_{0}$ & $\mathbf{N} / \mathbf{N}_{0}$ & Temperature & $1 / k_{n}$ & t (day) \\
\hline \multirow[t]{3}{*}{ ESB } & 25.30 & 246.02 & 1.71 & 5.85 & $20^{\circ} \mathrm{C} / 293.15 \mathrm{~K}$ & 131.15 & 236 \\
\hline & & & & & $25^{\circ} \mathrm{C} / 298.15 \mathrm{~K}$ & 110.20 & 194 \\
\hline & & & & & $30^{\circ} \mathrm{C} / 303.15 \mathrm{~K}$ & 93.12 & 164 \\
\hline \multirow[t]{3}{*}{ ESS } & 23.33 & 117.68 & 1.67 & 5.99 & $20^{\circ} \mathrm{C} / 293.15 \mathrm{~K}$ & 122.18 & 218 \\
\hline & & & & & $25^{\circ} \mathrm{C} / 298.15 \mathrm{~K}$ & 104.06 & 186 \\
\hline & & & & & $30^{\circ} \mathrm{C} / 303.15 \mathrm{~K}$ & 89.10 & 159 \\
\hline \multirow[t]{3}{*}{ CSB } & 23.82 & 136.30 & 1.73 & 5.78 & $20^{\circ} \mathrm{C} / 293.15 \mathrm{~K}$ & 129.04 & 226 \\
\hline & & & & & $25^{\circ} \mathrm{C} / 298.15 \mathrm{~K}$ & 109.53 & \\
\hline & & & & & $30^{\circ} \mathrm{C} / 303.15 \mathrm{~K}$ & 93.47 & 164 \\
\hline
\end{tabular}

Note: CSB - commercial strewed beef flavouring oil gravy; ESB - experimental strewed beef flavouring oil gravy; ESS - experimental sour soup flavouring oil gravy.

\section{Verification of the Prediction of Shelf Life}

To verify the predicted shelf life calculated using the Arrhenius equation, both ESB and ESS were consecutively stored at practical room temperature. Sensory evaluation was conducted during the whole storage process. As shown in Figure 1, the scores of both ESB and ESS were 47.17 and 47.67 at the beginning, respectively. The scores of colour, texture, odour were all 10 at the beginning, while the score of flavour and durance of fragrance still need improvement. The results of sensory evaluation indicated that both gravies had a bright tawny colour and moderate viscosity. In addition, ESB and ESS were abundant in soy sauce fragrance in both odour and flavour. The odour and flavour scores gradually decreased in the first four months and witnessed a dramatic decrease during the fourth to eighth months. The odour and flavour of soy sauce fragrance gradually disappeared, while the viscosity gradually increased. On the one hand, a decrease in scores might result from the

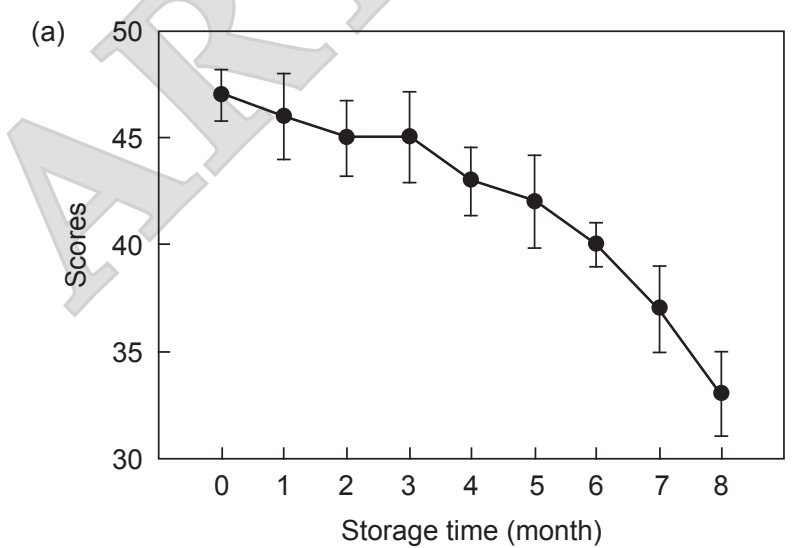

loss of origin flavour and the unpleasant flavour produced by the rancidity and deterioration of oil during long-term storage (Shen et al., 2018). Changes in the sensory profile may be indicators for the chemical oxidation index during storage. The formation of secondary metabolites may be the cause of unpleasant odours and flavours (Serfert et al., 2010). On the other hand, the fourth to eighth months during storage referred to July to October. High storage temperature further accelerated the deterioration process, which explained the sharp decrease in score.

$\mathrm{AV}$ and POV were also determined during storage, as shown in Figure 2. The results were consistent with the sensory evaluation scores. The AV of both ESB and ESS increased from approximately 2.00 to $9.20 \mathrm{mg} / \mathrm{g}$, while the POV increased from 0.025 to $0.180 \mathrm{~g} / 100 \mathrm{~g}$. AV and POV accelerated at the fifth month, and the growth rate still increased even with decreasing storage temperature. This reminded us that oil deterioration is an irreversible process and would accelerate until the end point.

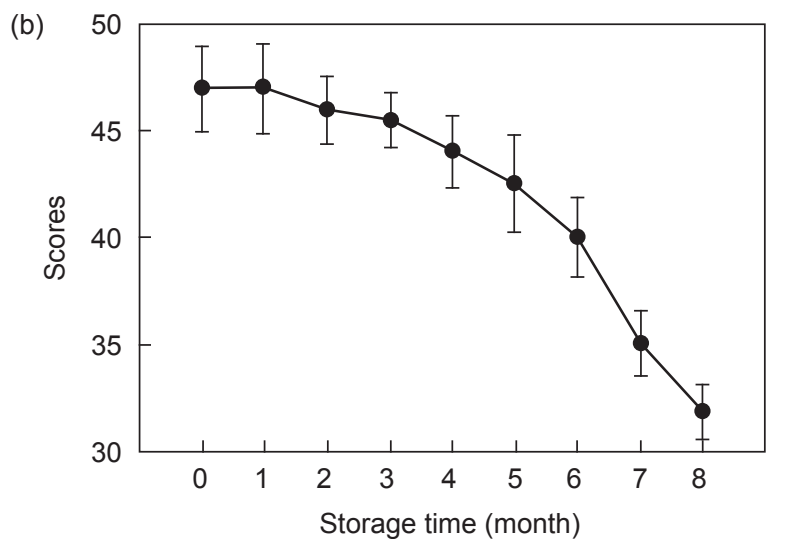

Figure 1. Changes of sensory evaluation scores in flavouring oil gravy during storage at room temperature. (a) Experimental strewed beef flavouring oil gravy; (b) experimental sour soup beef flavouring oil gravy. 

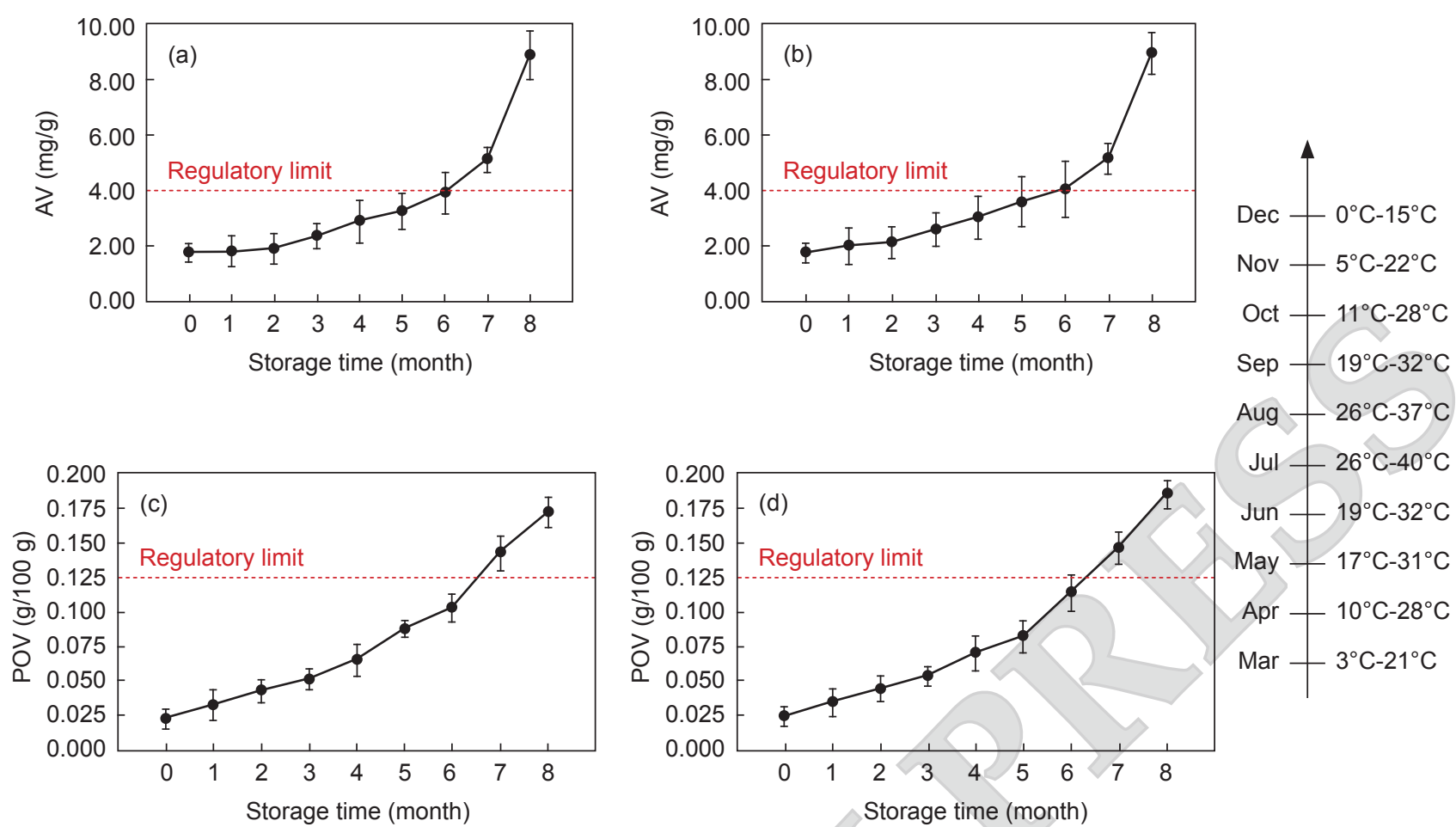

Figure 2. Changes of $A V$ and $P O V$ in flavouring oil gravy during storage at room temperature (a) changes of $A V$ in experimental strewed beef flavouring oil gravy, (b) changes of $A V$ in experimental sour soup beef flavouring oil gravy, (c) changes of POV in experimental strewed beef flavouring oil gravy, and (d) changes of POV in experimental sour soup beef flavouring oil gravy.

\section{CONCLUSION}

The results of this study indicated that colour differences between pilot gravies before and after storage were less significant than those of commercial gravy, which might be favoured by consumers. In addition, the shelf life of pilot gravies was slightly longer than that of commercial gravy. The predicted shelf life was shortened by 30 days for every $5^{\circ} \mathrm{C}$ rise between $20^{\circ} \mathrm{C}$ and $30^{\circ} \mathrm{C}$. The results of imitated storage indicated that $\mathrm{AV}$ and $\mathrm{POV}$ exceeded the regulatory limit after six months of consecutive storage and were close to the prediction model values. Therefore, we recommended that flavouring oil gravy made of RPO should be stored at room temperature and should be consumed within six months. Furthermore, the shelf-life model presented in this study provides a direction for selecting the storage temperature, which will be useful for shelf-life management combined with the target market.

\section{ACKNOWLEDGEMENT}

This work was supported by the National Natural Science Foundation of China (No. 31972036 and No. 32061160476) and PORTSIM (No. 038/2015).

\section{REFERENCES}

Alvarruiz, A; Pardo, J E; Copete, M E; de Miguel, C; Rabadan, A; Lopez, E and Alvarez-Orti, M (2020). Evolution of virgin olive oil during long-term storage. J. OLEO Sci., 69(8): 809-814.

Antonis, K (2019). Alterations of PET material physical properties during storage of olive oil. Food Packag. Shelf Life, 21: 100336.

Burri, B J (2012). Evaluating global barriers to the use of red palm oil as an intervention food to prevent vitamin A deficiency. Compr. Rev. Food. Sci. Food Saf., 11(2): 221-232.

Calligaris, S; Manzocco, L; Anese, $\mathrm{M}$ and Nicoli, M C (2016). Shelf-life assessment of food undergoing oxidation - A review. Crit. Rev. Food Sci. Nutr., 56(11): 1903-1912.

Catanzaro, R; Zerbinati, N; Solimene, U; Marcellino, M; Mohania, D; Italia, A; Ayala, A and Marotta, F (2016). Beneficial effect of refined red palm oil on lipid peroxidation and monocyte tissue factor in HCV-related liver disease: A randomised controlled study. Hepatobiliary Pancreat. Dis. Int., 15(2): 165172. 
Chinese Standard (2016a). GB 5009.227 Food safety national standards - determination of peroxide value in food samples. Standards Press, China.

Chinese Standard (2016b). GB 5009.229 Food safety national standards - determination of acid value in food samples. Standards Press, China.

David, K; Shirley, A T; Arnis K; Scott W and Susanne K C (2000). Cholesterol vehicle in experimental atherosclerosis. 22. Refined, bleached, deodorized (RBD) palm oil, randomised palm oil and red palm oil. Nutr. Res., 20(6): 887-892.

Guiotto, E N; Ixtaina, V Y; Nolasco, S M and Tomas, M C (2014). Effect of storage conditions and antioxidants on the oxidative stability of sunflowerchia oil blends. J. Am. Oil Chem. Soc., 91(5): 767-776.

Gulia, N; Dhaka, V and Khatka, B (2014). Instant noodles: Processing, quality and nutritional aspects. Crit. Rev. Food Sci. Nutr., 54: 1386-1399.

Huyan, Z Y; Ding, S X; Mao, X H; Wu, C E and Yu, X $Z$ (2019). Effects of packaging materials on oxidative product formation in vegetable oils: Hydroperoxides and volatiles. Food Packag. Shelf Life, 21: 100328.

Huh, I S; Kim, H; Jo, H K; Lim, C S; Kim, J S; Kim, S J; Kwon, O; Oh, B and Chang, N (2017). Instant noodle consumption is associated with cardiometabolic risk factors among college students in Seoul. Nutr. Res. Pract., 11: 232-239.

Katengua-Thamahane, E; Marnewick, J L; Ajuwon, O R; Chegou, N N; Szucs, G; Ferdinandy, P; Csont, T; Csonka, C and Van Rooyen, J (2014). The combination of red palm oil and rooibos show anti-inflammatory effects in rats. J. Inflamm. (Lond), 11: 41-52.

Kim, J; Shin, E C; Lim, H J; Yoon, M; Yang, H; Park, J; Park, E; Yoo, H; Baek, J and Cho, S (2015). Thermal oxidative stability of various vegetable oils used for the preparation of the seasoned laver Pyropia spp. Fish. Aquatic Sci., 18(1): 21-26.

Kwak, H S; Ahn, B H; Kim, H R and Lee, S Y (2015). Identification of sensory attributes that drive the likeability of Korean rice wines by American panelists. J. Food Sci., 80(6): S161-S170.

Manzini, R; Accorsi, R; Piana, F and Regattieri, A (2017). Accelerated life testing for packaging decisions in the edible oils distribution. Food Packag. Shelf Life, 12: 114-127.

Mizrahi, S (2000). Accelerated shelf-life tests. The Stability and Shelf-life of Food (Kilcast, D and Subramaniam, P eds.). Elsevier Science, Boca Raton. p. 107-125.

$\mathrm{Ng}, \mathrm{M} \mathrm{H}$; Choo, Y M; Ma, A N; Chuah, C H and Hashim M A (2004). Separation of vitamin E (tocopherol, tocotrienol, and tocomonoenol) in palm oil. Lipids, 39(10): 1031-1035.

Oguntibeju, O O; Esterhuyse, A J and Truter, E J (2009). Red palm oil: Nutritional, physiological and therapeutic roles in improving human wellbeing and quality of life. Brit. J. Biomed. Sci., 66(4): 216222.

Serfert, Y; Drusch, S and Schwarz, K (2010). Sensory odour profiling and lipid oxidation status of fish oil and microencapsulated fish oil. Food Chem., 123(4): 968975

Shen, L; Chen, X; Lee, D S; Zhu, X T; Chen, M and Yam, K L (2018). Effects of diffusion controlled release of tocopherol on lipid oxidation. Food Packag. Shelf Life, 17: 129-133.

Wang, D D and Hu, F B (2017). Dietary fat and risk of cardiovascular disease: Recent controversies and advances. Annu. Rev. Nutr., 37: 423-446.

Wergeland, A; Bester, D J; Sishi, B J N; Engelbrecht, A M; Jonassen, A K and Van Rooyen, J (2011). Dietary red palm oil protects the heart against the cytotoxic effects of anthracycline. Cell Biochem. Funct., 29(5): 356-364.

Wu, X J; Wu, S M; Ji, M and Yoong, J H (2018). Influence of red palm oil on the physicochemical and sensory qualities of flavouring oil gravy for instant noodles. RSC Adv., 8: 1148-1158.

Yi, J Y; Anderson, M L and Skibsted, L H (2011). Interactions between tocopherols, tocotrienols and carotenoids during autoxidation of mixed palm olein and fish oil. Food Chem., 127(4): 1792-1797.

Zhao, P; Zhang, X; Jin, Y and Xu, L Y (2021). Longterm stability of blends of sesame oil or soybean oil with tuna oil under daily use conditions. J. Am. Oil Chem. Soc., 98(9): 933-941. 